\title{
FASCINATION FOR CARS?
}

Dear Reader,

In 2013, the average age of private buyers of new cars in Germany was 52.4 years. Only just over a quarter of them were younger than 45 . This proportion has almost halved within the past 18 years. So what has happened to the all-important age group between 18 and 30? Where is their fascination for cars? Do young people in Germany still want a car at all, or do they have completely different priorities? Is the car an endangered species?

It is a fact that people in this age group, as buyers of used cars and later new cars, play a key role in carmakers' strategies. It is also a fact that this age group in particular is complementarily mobile including virtual mobility via mobile consumer devices. And thirdly, it is a fact that this primarily urban target group carefully considers whether owning a car is necessary, also for cost reasons. And this is precisely the problem facing carmakers. Until the 1980s, the car was a symbol of independence, but there has been a fundamental change since then. Today, independence means above all flexibility and connectivity. Having a car of one's own can wait until later, when it is perhaps needed to transport a family.

Car sharing is an obvious concept, but it is only temporarily effective in individual locations. Electric cars may be a future solution, but they present customers with the next emissions and environmental dilemma: The increasing use of brown coal for generating electricity might mean that, in the mainly emotional and uninformed discussions, the internal combustion engine as an (alleged) environment killer will be quickly replaced by the electric motor as an environmental pollutant.

Firstly, what is absolutely essential is the rapid development of automotive connectivity: Smartphones must become part of the connected car. Secondly, modern driver assistance systems must allow partly or fully automated driving as soon as possible - and at reasonable prices. Interesting approaches could be seen at this year's CES and in Detroit. And thirdly, it is vitally important to continue to develop internal combustion engines, as these will still accompany us over the coming decades. For one thing is certain: The group of car buyers up to the age of 45 is not anti-car. It is just that their fascination for cars is defined in a different way. For them, "automobile" means "autonomously mobile”.

Best regards,

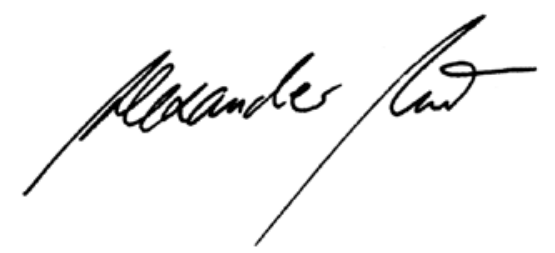

DR. ALEXANDER HEINTZEL, Editor in Chief Wiesbaden, 14 January 2014

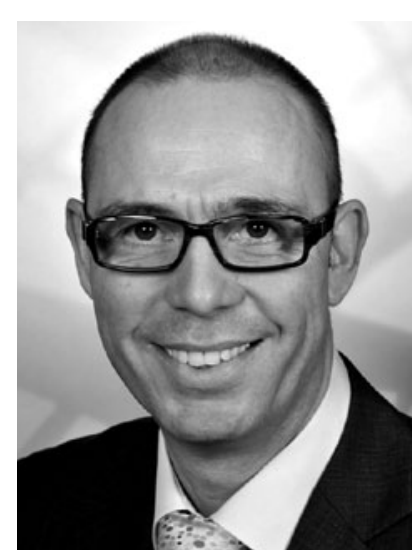

